\title{
Modeling the probability of giving birth at health institutions among pregnant women attending antenatal care in West Shewa Zone, Oromia, Ethiopia: a cross sectional study
}

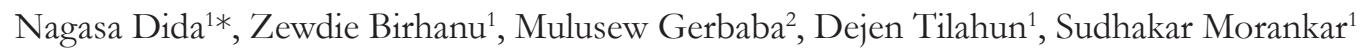

1.College of Public Health and Medical Sciences, Department of Health Education and Behavioral Sciences, Jimma University, Jimma, Ethiopia

2.College of Public Health and Medical Sciences, Department of Population and Family Health, Jimma University, Jimma, Ethiopia

\begin{abstract}
Background: Although ante natal care and institutional delivery is effective means for reducing maternal morbidity and mortality, the probability of giving birth at health institutions among ante natal care attendants has not been modeled in Ethiopia. Therefore, the objective of this study was to model predictors of giving birth at health institutions among expectant mothers following antenatal care.

Methods: Facility based cross sectional study design was conducted among 322 consecutively selected mothers who were following ante natal care in two districts of West Shewa Zone, Oromia Regional State, Ethiopia. Participants were proportionally recruited from six health institutions. The data were analyzed using SPSS version 17.0. Multivariable logistic regression was employed to develop the prediction model.

Results: The final regression model had good discrimination power $(89.2 \%)$, optimum sensitivity $(89.0 \%)$ and specificity $(80.0 \%)$ to predict the probability of giving birth at health institutions. Accordingly, self efficacy (beta $=0.41$ ), perceived barrier (beta $=-0.31)$ and perceived susceptibility (beta $=0.29$ ) were significantly predicted the probability of giving birth at health institutions.

Conclusion: The present study showed that logistic regression model has predicted the probability of giving birth at health institutions and identified significant predictors which health care providers should take into account in promotion of institutional delivery.
\end{abstract}

Key word: Institutional delivery, intention, ANC, probability

African Health Sciences 2014; 14(2):288-298

DOI: http://dx.doi.org/10.4314/ahs.v14i2.3

\section{Background}

The fifth Millennium Development Goal (MDG-5) is to reduce maternal mortality by three quarters between 1990 and 2015. Yet, maternal mortality remains unacceptably high across much of the developing world. Given the apparently slow progress in the countries withthe highest levels of maternal mortality, this will be hard to achieve [1, 2].

In sub-Saharan Africa, a woman's risk of dying from treatable or preventable complications of pregnancy

\section{*corresponding author: \\ Nagasa Dida \\ College of Public Health and Medical Sciences, Department of Health Education and Behavioral Sciences, Jimma University, Jimma, Ethiopia \\ Email:nadibefe@yahoo.com}

and childbirth over the course of her lifetime is 1 in 22 , compared to 1 in 7,300 in the developed regions [3]. Similar to other Sub-Saharan African countries, Ethiopian is amongst the countries with the highest maternal mortality ratio. According to Ethiopian Demographic and Health Survey (EDHS) 2005, maternal mortality was 673/100,000 live births [4].

Research has shown that adequate use of Antenatal Care (ANC) and delivery services can reduce maternal deaths from 10 to $45 \%$, especially in the developing countries $[5,6]$ and progress has been documented with regard to utilization of maternal health services. For instance, the proportion of pregnant women in the developing world who had at least one antenatal care visit increased from slightly more than half at the beginning of the 1990s to almost three quarters a decade later [7]. However, every year about 536000 women die of complications during pregnancy or childbirth, $99 \%$ of them in developing countries [7].

In Ethiopia, according to the MDGs 2010 report, 
antenatal care use has reached 59.4\%. Nevertheless deliveries attended by skilled health personnel have been increased only by $20.3 \%$. This implies that safe delivery service is being improving less than expected [8]. Likewise, Ethiopia is among the leading countries of high infant and neonatal mortality rate. For instance, in the year 2001-2005, the infant mortality rate was 77 per 1,000. During the same year, in Oromia region, neonatal death was 40 per 10,000 live births [4]. Evidence has shown that most of the neonatal death is because of unsafe delivery [9].

Underutilization of institutional delivery service is a common problem for developing countries in the effort undertaken to reduce maternal mortality; many mothers give birth at their home [10]. Home delivery is usually the cheapest option, but it has increased risks of infection and complications. Evidence has demonstrated that choice of place of delivery is influenced by various factors including perceptions that their most recent labor and delivery could have endangered their own or their baby's health, fear for pregnancy complications, perceived susceptibility to birth complication, perceived benefit of delivering at health institutions, and perceived barriers to use safe delivery services [10-12].

In many studies, the odds of pregnant mothers' exposure to media, ante natal care visit, maternal and husband's socio-economic and cultural characteristics were significantly associated with giving birth at health institutions [9, 11-15]. However, studies are very limited to model the odds of giving birth at health institutions among expectant mothers, particularly in the study setting. Thus, the purposes of this study was to develop a better logic regression model which can accurately predict the probability of giving birth at health institutions with an optimum sensitivity and specificity among ANC followers. More expressively, we intended to answer two research questions. Firstly, "What are the significant factors which predict the probability of giving birth at health institutions?" Secondly, "Which logic regression models accurately predict the probability of giving birth at health institution?"

\section{Methods}

Study setting and design: A facility based cross sectional study design was conducted over a period of twenty 21 days (from January 2, 2010 to January 23, 2010) at six health institutions found in two districts (Gindaberet and Abuna Gindaberet) of West Shewa
Zone of Oromia National Regional State. According to the district health report there were 8,624 pregnant women in the two districts. One district Hospital and five health centers are found in the two districts. In both districts, antenatal care coverage was higher (54\%) compared to the national statistics which was about $26 \%$ [16].

Sample size and sampling procedures: Single population proportion formula was used to calculate sample size with the assumption of $95 \%$ level of confidence interval, $5 \%$ margin of error and $26 \%$ of the proportion $(\mathrm{P})$ of mothers who give birth at government health institutions in Ethiopia [17]. Considering 10\% non-response rate; the final sample size was 326. One district hospital and all health centers found in both districts were included in the study. Then, the sample size was proportionally allocated to each health facility taking into account the number of pregnant women who were served under each health facility in the previous one month. Finally, eligible mothers who came to health institution for antenatal care service was interviewed consecutively until the required sample size were fulfilled.

\section{Measurement and data collection methods}

Instruments were adapted from literatures and it consisted of three parts, namely socio-demographic and obstetrics characteristics, past behaviors and experiences, and beliefs and perception. Belief instruments were constructed based on the theoretical framework of Health Belief Model (HBM). HBM is a socio-psychological model that attempts to explain and predict health behaviors in terms of health beliefs. The model extensively applied in predicting health behaviors [18] and it states that individual's perceptions of the threat posed by a health problem (susceptibility, severity), the benefits of avoiding the threat, and factors influencing the decision to act (barriers, cues to action, and self-efficacy) determines individual readiness to perform the recommended behavior [18,19].

These belief based items were scored on a five-point Likert scale ranging from strongly disagree (1) to strongly agree (5). Confirmatory factor analysis was done to check the extent to which these items are measuring the same underlying factor. Factors with egenvalue $>$ 1 were retained after Varimax rotation method. The analysis produced five factors which named as perceived susceptibility (variance explained $=17.18 \%$ ), perceived severity (variance explained $=15.72 \%$ ), perceived 
benefits (variance explained $=10.80 \%$ ), perceived barriers (variance explained $=10.82 \%$ ) and self-efficacy (variance explained $=10.44 \%$ ). Finally, the internal consistence of these scales was assessed by Cronbach alpha $(\dot{\alpha})$ and it indicated an evidence of internally consistent scale ( $\dot{\alpha}$ ranges from 0.69 to 0.84 ). Summative score of each scale was used for further analysis. Cues to action were assessed by yes/no item and directly used for analysis. Similarly, knowledge was measured by yes/no items and all correct answers were coded as ' 1 ' and incorrect answers were coded as ' 0 '. The outcome variable (intention to give birth at health institution) was measured directly by a single item. Clients were asked "where do you intended to give birth for your current pregnancy?" The instrument was translated into Afan Oromo (local language) and was pre-tested. Data collectors and supervisors were trained for two days. Exit interview were conducted with consecutive ANC clients.

\section{Statistical analysis}

The data were analyzed by SPSS version 17.0. Multivariate logistic regression analysis was done to determine the prediction model with corresponding p-value of $<0.05$ and $95 \%$ Confidence Interval. Four logistic regression models were developed. In the first model, the effect of socio-demographic characteristics was examined. The second model consisted of past behaviors and experiences of the participants. In the third model, variables related to perception of the mothers which was primarily based on the constructs of HBM were included. The last model consisted of all explanatory variables which had statistically significant effect on outcome variable $(\mathrm{P}<0.05)$ in the first, second and third models. Each model was built as follows; first, we run a baseline model including all cases (with outliers). Then, to determine the impact of outliers and influential case, cook's distance and standard residuals were computed. We excluded a case with a standardized residual larger than 3.0 or smaller than -3.0 and cook's distance greater than 1.0 from the analysis. Then, regression model without outliers and influential cases was compared with the model with outliers. When the accuracy rate of the revised model (without outliers and influential cases) was less than $2 \%$, we were interpreted the baseline model. In addition, to avoid the over fitting of the model and to select the model which best fit the data; each model was cross-validated. We have used holdout cross-validation method with $80-20$ version. In this validation strategy, cases were randomly divided into two subsets: a training sample containing $80 \%$ of the cases and a holdout sample containing the remaining $20 \%$ of the cases. The training sample was used to derive the logistic regression model and the holdout sample was classified using the coefficients based on the training sample. If the classification accuracy rate of the holdout sample was within $10 \%$ of the training sample, it is deemed sufficient evidence of the utility of the logistic regression model. The goodness of fit was evaluated with chi square goodness of fit for the baseline model. Likewise, the predictive accuracy rate was determined by the value of Hosmer-Lemeshow goodness-of-fit statistic. Finally, Receiver Operating Characteristic (ROC) was used to evaluate the discrimination power of each model. In a ROC curve the true positive rate (Sensitivity), that is the probability of detecting women who truly give birth at health institution, was plotted in function of the false positive rate (1-Specificity) for an entire range of possible cut points (0.5). The area under the curve gives the discrimination power of the model. The larger the area, the better the classifier performs and more discrimination power. The optimal sensitivity/ specificity was obtained from the point (* see fig 1 ) nearest to the left upper corner of the box. We have used the following criteria to judge the discrimination power, $0.90-1.0=$ excellent, $0.80-.90=$ good, $0.70-.80$ $=$ fair, $0.60-.70=$ poor and $0.50-.60=$ fail. For each model, beta coefficients estimates were used to estimate the probability of giving birth at health institutions.

Then, the regression equation model could be written as $\operatorname{logit}(\mathrm{p})=\mathrm{b}_{0}+\mathrm{b}_{1} \mathrm{X}_{1}+\mathrm{b}_{2} \mathrm{X}_{2}+\mathrm{b}_{3} \mathrm{X}_{3}+\ldots+\mathrm{b}_{\mathrm{k}} \mathrm{X}_{\mathrm{k} ;}$ Where $\mathrm{p}$ is the probability of giving birth at health institutions, regression coefficients were represented by coefficients $b_{0}, b_{1}, b_{2}, \ldots b_{k}$, x represent the exogenous variables determining the intentions to deliver at health institutions. This equation could be transformed to $\mathrm{p}=\exp ^{\text {logit }(\mathrm{P})} / 1+\exp ^{\text {logit }(\mathrm{p})}$ to obtain the probability of giving birth at health instittions.

\section{Ethical consideration}

Ethical issue was approved by Ethical Review Board of Jimma University. Official permission to conduct the study was obtained from the respective District Health Offices and verbal informed consent was sought from each participant. 


\section{Results}

\section{Demographic characteristics of the} participants

Three hundred twenty two Ante Natal Care clients were participated in the study producing response rate of $98.7 \%$. $254(78.9 \%)$ of the participants were recruited from health centers the remaining were from district hospital. The mean age of the participants were $27.7 \pm 6.0$ (range $=18-44$ ) and the majority of them were residing in rural areas (86.6\%). Almost all of them (95.3\%) were married and live together with their partners. Occupationally, $270(83.9 \%)$ of the participants were farmers. Nearly, all of the participants (99.1\%) were Oromo in ethnicity. In terms of religion, protestant affiliation accounts the largest percentage, 211 (65.5\%). Concerning educational background, more than half, 207 (64.3\%), of the participants cannot read and write and only $9(2.8 \%)$ were completed grade twelve.

\section{Effect of socio-demographic characteristics}

Two hundred twenty two $(68.9 \%)$ of the participants were intended to give birth at health institutions. The effect of socio-demographic characteristics of the par- ticipants on odds of giving birth at health institutions was presented in table1. Accordingly, only four variables; household monthly income $(p=0.001)$, health institution $(p=0.020)$, mother occupation $(p=0.038)$ and husband occupation $(\mathrm{p}=0.044)$ had significant effect on the odds of giving birth at health institutions. .

In this model, the effect of influential and extreme cases was not observed as the predictive accuracy rate of the model was improved only by $1.6 \%$ when outliers excluded. In cross validation, the probability for the model chi-square (65.598) testing overall relationship was $<0.001$ and the classification accuracy rate of the holdout sample was fallen within $10 \%$ of the training sample (accuracy rate for training $\mathrm{g}$ sample $=73.2 \%$ and holdout $=81.5 \%$ ). This supports, the interpretation of the model using the full data set. However, the pattern of significance of the relationships between the individual independent variables and the dependent variable did not support the interpretation of the model using the full data set. In cross validation, only income remain significant ( $p=0.003$ ). Thus, it is deemed no sufficient evidence of the utility of this logistic regression model. This model was found to explain only 40.3\% (R Square) of the variability in outcome variable.

\begin{tabular}{|c|c|c|c|c|c|}
\hline Covariates & Beta & S.E. & Wald & Sig. & OR $(95 \% \mathrm{CI})$ \\
\hline Residence (urban*/rural) & -19.92 & 62.45 & 0.000 & 0.998 & $0.11(0.012 .35)$ \\
\hline Age of mother & 0.09 & 0.04 & 3.652 & 0.056 & $1.09(0.99-1.20)$ \\
\hline Age of husband & -0.03 & 0.03 & 1.137 & 0.286 & $0.96(0.89-1.03)$ \\
\hline Household monthly income & 0.02 & 0.00 & 12.447 & 0.000 & $1.02(1.00-1.02)$ \\
\hline Time taken to reach ( $\leq 2 \mathrm{hrs} * />2 \mathrm{hrs})$ & 0.25 & 0.36 & 0.494 & 0.482 & $1.29(0.63-2.64)$ \\
\hline Cost of travel (<1USD*/>1USD) & 0.65 & 0.36 & 3.169 & 0.075 & $1.91(0.93-3.91)$ \\
\hline $\begin{array}{l}\text { Health institutions } \\
\text { centers) }\end{array}$ & -1.58 & 0.67 & 5.439 & 0.020 & $0.20(0.05-0.77)$ \\
\hline Religion (Christian*/ Wakefena) & -0.54 & 0.34 & 2.492 & 0.114 & $0.58(0.29-1.14)$ \\
\hline Mother occupation (Farmers*/others) & -1.33 & 0.64 & 4.285 & 0.038 & $0.26(0.07-0.93)$ \\
\hline Husband occupation (famers*others) & 1.04 & 0.51 & 4.048 & 0.044 & $2.84(1.02-7.85)$ \\
\hline $\begin{array}{l}\text { Husband education (not attended formal } \\
\text { education* / formal education }\end{array}$ & 0.06 & 0.34 & 0.034 & 0.854 & $1.06(0.54-2.08)$ \\
\hline $\begin{array}{l}\text { Mother education (not attended formal } \\
\text { education* / formal education }\end{array}$ & 0.81 & 0.55 & 2.212 & 0.137 & $2.26(0.77-6.65)$ \\
\hline
\end{tabular}

Effect of past behaviors and experiences

Within this category of variables, age at first delivery, being given health information during visit and making decision by herself and gravid had significantly predicted the probability of giving birth at health institution $(\mathrm{p}<0.05)$ (table2). The impact of outliers and influential cases were also not observed in this model; classification accuracy rate was increased only by $0.5 \%$ without outliers and influential cases. In 
cross-validation analysis, the relationship between independent variables and dependent variable was statistically significant; chi-square goodness of fit was 95.546 at p-value 0.001. The classification accuracy rate also supported the interpretation of the full model; accuracy rate for the training sample was $78.0 \%$ and of the holdout sample was $72.4 \%$. In addition, the pattern of relationship and sign analysis supported the model with full data set. However, this model suffered from inconsistency of the significant variables. For instance, being given information was significant predictor in the model with full data set. Nevertheless, the association disappeared in the cross validation model. This model was found to be better than the previous in terms of validity and variance explained.

Table 2: Predicting the probability of giving birth at health institutions from past behaviors, and obstetric characteristics, West Shewa, Ethiopia, January 2010

\begin{tabular}{|c|c|c|c|c|c|}
\hline Covariates & $\mathrm{B}$ & S.E. & Wald & Sig. & OR $(95 \% \mathrm{CI})$ \\
\hline Age at first delivery & 0.33 & 0.09 & 12.064 & 0.001 & $1.39(1.15-1.68)$ \\
\hline Current pregnancy planned (yes*/no) & -0.59 & 0.49 & 1.414 & 0.234 & $0.55(0.21-1.47)$ \\
\hline $\begin{array}{l}\text { Mother attend ANC for the last birth } \\
\text { (yes*/no) }\end{array}$ & -0.61 & 0.56 & 1.180 & 0.277 & $0.54(0.18-1.63)$ \\
\hline Health information given during visit & -2.41 & 1.19 & 4.103 & 0.043 & $0.09(0.01-0.93)$ \\
\hline $\begin{array}{l}\text { Decision where to deliver (herself*/ } \\
\text { others) }\end{array}$ & -0.81 & 0.27 & 9.355 & 0.002 & $0.45(0.26-0.75)$ \\
\hline Number of live birth $\left(<5^{*} / \geq 5\right)$ & 0.38 & 0.81 & 0.220 & 0.639 & $1.46(0.29-7.14)$ \\
\hline Experience of abortion (yes*/no) & -0.19 & 0.49 & 0.151 & 0.697 & $0.83(0.32-2.17)$ \\
\hline Experience of still birth (yes*/no) & 0.77 & 0.68 & 1.300 & 0.254 & $2.17(0.57-8.26)$ \\
\hline Experience of infant death (yes*/no) & 0.23 & 0.49 & 0.226 & 0.634 & $1.26(0.48-3.29)$ \\
\hline Gravida $\left(<5^{*} / \geq 5\right)$ & 1.22 & 0.50 & 5.998 & 0.014 & $3.39(1.28-9.05)$ \\
\hline $\operatorname{Para}\left(<5^{*} / \geq 5\right)$ & -0.82 & 0.87 & 0.881 & 0.348 & $0.44(0.08-2.43)$ \\
\hline $\begin{array}{l}\text { Place of lastdelivery (health institution*/ } \\
\text { home) }\end{array}$ & -20.63 & 5031.73 & 0.000 & 0.997 & $0.00(0.00-)$ \\
\hline Constant & 14.15 & 5031.73 & 0.000 & 0.998 & 1393237.584 \\
\hline
\end{tabular}

\section{Effect of perception and knowledge}

The effect of beliefs and perceptions related to the constructs of health belief model was examined and the result was displayed in table 3. In this regress model, perceived susceptibility, severity, perceived barriers, self efficacy were significantly predicted the probability of giving birth at health institutions $(\mathrm{p}<0.05)$. In addition, cues to action had significant effect on the predicted probability $(\mathrm{p}<0.05)$.

Outliers and influential cases had no effect on the model and predictive accuracy rate. In cross validation, the overall significance of the model supported the interpretation of the model using the full data set $\left(\mathrm{X}^{2}\right.$ goodness of fit $=101.977, \mathrm{p}$-value $\left.=0.001\right)$. The accuracy rate was $83.2 \%$ and $78.8 \%$ for the training sample and holdout sample, respectively which satisfied the minimum requirement to support the baseline model. The significance level of all variables in the baseline model matched with the significance level in the cross validation analysis except perceived benefits which was significant in the cross validation but did not in the baseline model. Sign analysis also revealed that the significant level of each variable was matched. 
Table 3: Predicting the probability of giving birth at health institution from perceptions about pregnancy and delivery at health institution, West Shewa, Ethiopia, January 2010

\begin{tabular}{|l|l|l|l|l|l|}
\hline Covariates & B & S.E. & Wald & Sig. & OR (95\%CI) \\
\hline Perceived susceptibility & 0.47 & 0.10 & 22.267 & 0.000 & $1.62(0.51-0.76)$ \\
\hline Perceived severity & 0.19 & 0.09 & 4.787 & 0.029 & $1.22(1.02-1.45)$ \\
\hline Perceived benefits & 0.16 & 0.11 & 2.309 & 0.129 & $1.17(0.96-1.44)$ \\
\hline Perceived barriers & -0.25 & 0.07 & 10.989 & 0.001 & $0.28(0.11-0.49)$ \\
\hline Self efficacy & 0.49 & 0.12 & 16.057 & 0.000 & $1.65(1.29-2.10)$ \\
\hline Knowledge & 0.12 & 0.08 & 2.485 & 0.115 & $1.14(0.97-1.33)$ \\
\hline $\begin{array}{l}\text { Cues to action } \\
\text { Ever seen mother suffered from } \\
\text { pregnancy complication (yes*/no) }\end{array}$ & 0.02 & 0.46 & 0.004 & 0.953 & $1.03(0.42-2.54)$ \\
\hline $\begin{array}{l}\text { Ever seen mothers die of pregnancy } \\
\text { (yes*/no) }\end{array}$ & -1.00 & 0.43 & 5.459 & 0.019 & $0.37(0.16-0.85)$ \\
\hline $\begin{array}{l}\text { Ever heard any message about } \\
\text { pregnancy from media (yes*/no) }\end{array}$ & -.032 & 0.34 & 0.846 & 0.358 & $0.73(0.37-1.43)$ \\
\hline $\begin{array}{l}\text { Health professional informed where } \\
\text { to deliver (yes*/no) }\end{array}$ & -1.68 & 0.66 & 6.484 & 0.011 & $0.19(0.05-0.68)$ \\
\hline $\begin{array}{l}\text { Experienced any symptoms (yes*/ } \\
\text { no) }\end{array}$ & -0.13 & 0.36 & 0.133 & 0.715 & $0.88(0.43-1.78)$ \\
\hline *reference category & & & & \\
\hline
\end{tabular}

\section{Predictors of intention to give birth at health institutions}

The forth model was built from all significant variables (beta coefficient significantly different from zero). In this regression model, only five variables (perceived susceptibility, perceived barriers, self efficacy, being able to make decision on her own and being informed where to delivery $(\mathrm{p}<0.05))$ were significantly predicted the probability of giving birth at health institution (table 4). Chi-square test of goodness of fit showed that this regression model can predict the probability $\left(x^{2}=118.026, p=0.001\right)$ with classification accuracy rate of $84.2 \%$. When cross validated, the overall significance of the model was remain significant $\left(x^{2}=94.278\right.$, $\mathrm{p}=0.001)$. The classification accuracy rate was $81.5 \%$ and $83.0 \%$ for the training sample and holdout sample, respectively. In addition, in cross validation, no sign mismatch was observed with regard to beta coefficient estimates. However, the significance level of some variables was disappeared in cross validation (perceived susceptibility become insignificant) while other variable become significant (e.g. Household monthly income). Although the cross validation statistics did not fully support it, this model can be utilized to explain factors which significantly affect delivery at health institutions among these populations. 
Table 4: Predictors of the probability of giving birth at health institutions among ANC attendants, West Shewa, Ethiopia, January 2010

\begin{tabular}{|c|c|c|c|c|c|}
\hline Covariates & $\mathrm{B}$ & S.E. & Wald & Sig. & AOR $(95 \% \mathrm{CI})$ \\
\hline Household monthly income & 0.01 & 0.00 & 2.907 & 0.088 & $1.00(1.00-1.00)$ \\
\hline Age at first delivery & 0.05 & 0.11 & 0.252 & 0.615 & $1.05(0.85-1.30)$ \\
\hline Who made decision (herself*/others) & 1.23 & 0.42 & 8.594 & 0.003 & $3.42(1.50-7.78)$ \\
\hline Gravida $\left(<5^{*} / \geq 5\right)$ & 0.49 & 0.39 & 1.573 & 0.210 & $1.64(0.76-3.58)$ \\
\hline Knowledge & 0.13 & 0.09 & 2.301 & 0.129 & $1.14(0.96-1.34)$ \\
\hline Perceived Susceptibility & 0.29 & 0.11 & 7.397 & 0.007 & $1.74(1.59-1.92)$ \\
\hline Perceived Severity & 0.16 & 0.09 & 2.959 & 0.085 & $1.18(0.98-1.41)$ \\
\hline Perceived benefit $\mathrm{s}$ & 0.09 & 0.11 & 0.671 & 0.413 & $1.09(0.88-1.37)$ \\
\hline Perceived barriers & -0.31 & 0.09 & 11.602 & 0.001 & $0.36(0.02-0.89)$ \\
\hline Self efficacy & 0.41 & 0.14 & 9.028 & 0.003 & $1.50(1.15-1.95)$ \\
\hline $\begin{array}{l}\text { Ever seen someone die of } \\
\text { pregnancy }\left(\text { yes }^{*} / \text { no }\right)\end{array}$ & -0.33 & 0.43 & 0.588 & 0.443 & $0.72(0.31-1.67)$ \\
\hline $\begin{array}{l}\text { Health professionals informed where } \\
\text { to give birth }\left(\mathrm{yes}^{*} / \mathrm{no}\right)\end{array}$ & -1.59 & 0.73 & 4.731 & 0.030 & $0.20(0.05-0.86)$ \\
\hline $\begin{array}{l}\text { Husband occupation (farmers*/ } \\
\text { others) }\end{array}$ & 0.48 & 0.55 & 0.751 & 0.386 & $1.61(0.55-4.77)$ \\
\hline $\begin{array}{l}\text { Mothers occupation } \\
\text { others) }\end{array}$ & -0.82 & 0.75 & 1.197 & 0.274 & $0.44(0.10-1.91)$ \\
\hline $\begin{array}{l}\text { Place of delivery for the last birth } \\
\text { (health institution*/home) }\end{array}$ & -1.11 & 0.72 & 2.404 & 0.121 & $0.33(0.08-1.34)$ \\
\hline
\end{tabular}

\section{Classification accuracy rate of the models}

The classification accuracy rate of each model to predict the event (giving birth at health institution) in the full model and cross validation holdout sample was presented in (table 5). Consequently, the overall accuracy of the first model to predict subjects intended to give birth in health institution (with a predicted probability of 0.5 or greater) was $72.7 \%$ with sensitivity of $81.5 \%$. The second and the third model had equal overall prediction accuracy rate $(84.4 \%)$. Forth model was found to have overall accuracy rate of $84.2 \%$ which was lower than the second and the third but better than the first regression model. The Hosmer-Lemeshow goodness of fit told us how closely the observed and predicted probabilities match and the null hypothesis was "the model fits" and $\mathrm{p}$ value $>0.05$ was expected. Thus, in all models, $\mathrm{P}>0.05$ and we accepted the null hypothesis. 
Table 5: classification accuracy rate of each model and cross validated holdout sample result (using prior probability of 0.50 )

\begin{tabular}{|c|c|c|c|c|c|c|}
\hline \multirow{3}{*}{\multicolumn{2}{|c|}{ Observed }} & \multicolumn{3}{|c|}{$\begin{array}{l}\text { Predicted group membership in } \\
\text { each model }\end{array}$} & \multirow{3}{*}{$\begin{array}{l}\text { Significance/ } \\
\text { Hosmer and } \\
\text { Lemeshow } \\
\text { Test }\end{array}$} & \multirow{3}{*}{$\begin{array}{l}\text { Amount of variance } \\
\text { explained/approximate } \\
\text { R square }(\%)\end{array}$} \\
\hline & & \multicolumn{3}{|c|}{ Place of delivery } & & \\
\hline & & Home & $\begin{array}{l}\text { He a l th } \\
\text { institution }\end{array}$ & $\begin{array}{l}\text { Percentage } \\
\text { Correct }\end{array}$ & & \\
\hline \multirow[t]{4}{*}{ Model 1} & Home & 53 & 41 & 56.4 & \multirow{3}{*}{$\begin{array}{l}\mathrm{X}^{2}=15.393, \\
\mathrm{p}=.052\end{array}$} & \multirow[t]{3}{*}{40.3} \\
\hline & Health institution & 32 & 141 & 81.5 & & \\
\hline & $\begin{array}{l}\text { Overall \% correctly } \\
\text { classified in original } \\
\text { data }\end{array}$ & & & 72.7 & & \\
\hline & $\begin{array}{l}\text { Overall \% correctly } \\
\text { classified in cross } \\
\text { validation }\end{array}$ & & & 81.5 & & \\
\hline \multirow[t]{4}{*}{ Model 2} & Home & 56 & 30 & 65.1 & \multirow{3}{*}{$\begin{array}{l}\mathrm{X}^{2}=14.295, \\
\mathrm{p}=0.074\end{array}$} & \multirow[t]{3}{*}{48.1} \\
\hline & Health institution & 17 & 199 & 92.1 & & \\
\hline & Overall Percentage & & & 84.4 & & \\
\hline & $\begin{array}{l}\text { Overall } \% \text { correctly } \\
\text { classified in cross } \\
\text { validation }\end{array}$ & & & 72.4 & & \\
\hline \multirow{4}{*}{$\begin{array}{l}\text { Model } \\
3\end{array}$} & Home & 56 & 30 & 65.1 & \multirow{3}{*}{$\begin{array}{l}\mathrm{X}^{2}=14.295 \\
\mathrm{p}=0.074\end{array}$} & \multirow[t]{3}{*}{48.1} \\
\hline & Health institution & 17 & 199 & 92.1 & & \\
\hline & Overall Percentage & & & 84.4 & & \\
\hline & $\begin{array}{l}\text { Overall } \% \text { correctly } \\
\text { classified in cross } \\
\text { validation }\end{array}$ & & & 78.7 & & \\
\hline \multirow[t]{4}{*}{ Model 4} & Home & 62 & 22 & 73.8 & \multirow{3}{*}{$\begin{array}{l}\mathrm{X}^{2}=3.853 \\
\mathrm{p}=0.870\end{array}$} & \multirow[t]{3}{*}{61.8} \\
\hline & Health institution & 18 & 151 & 89.3 & & \\
\hline & Overall Percentage & & & 84.2 & & \\
\hline & $\begin{array}{l}\text { Overall \% correctly } \\
\text { classified in cross } \\
\text { validation }\end{array}$ & & & 83.0 & & \\
\hline
\end{tabular}

To assess the discrimination power of each model at the probability of $0.5, \mathrm{ROC}$ was constructed and presented in fig 1 . The areas under the ROC were 0.818 , $0.814,0.869$ and 0.892 for the $1^{\text {st }}, 2^{\text {nd }}, 3^{\text {rd }}$ and $4^{\text {th }}$ model, respectively $(\mathrm{p}$-value $=0.001)$. The last model was found to have better discrimination power which means that in almost $89.2 \%$ of all possible pairs of subjects in which one has intention and no intention, this model will assign a higher probability to the subject with intention to give birth in health facility. In addition, a close look into these models showed that the last model was found to have a better utility considering the trade-off between true positive rate and false positive rate. The optimum sensitive and specificity of this model was $89 \%$ and $80 \%$, respectively. It was only this model which achieved an optimum sensitive and specificity to correctly classify those women who will give birth at health institutions and who will not. The remaining models, may be more affected by more false positive rate; meaning a mother may be incorrectly classified as intended to give birth 
at health institutions while actually not. This reflects that the last model's overall explanatory strength was good and it deemed the utility to predict the probability of giving birth at health institution among pregnant women following ANC service.

\section{ROC Curve}
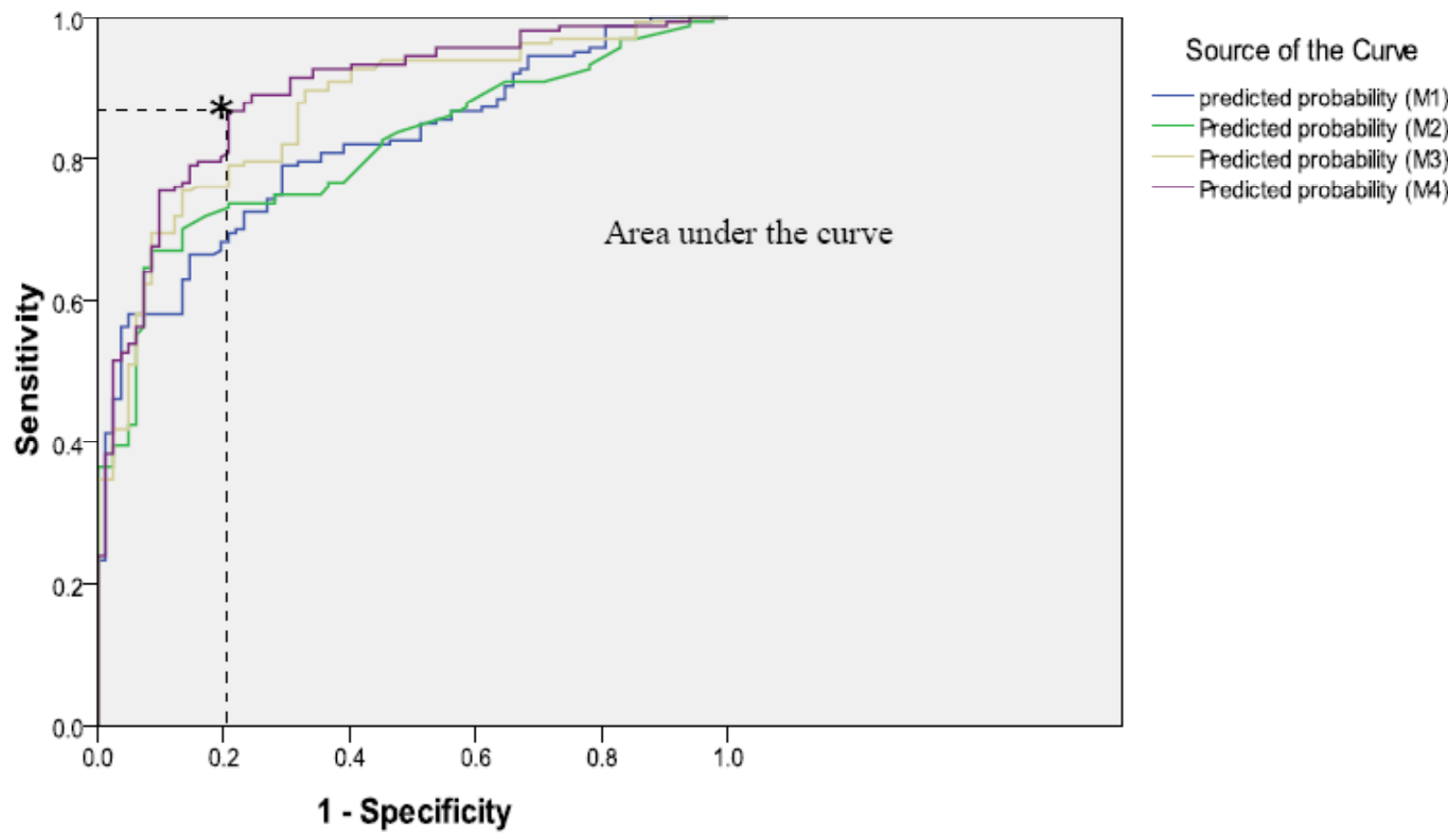

Diagonal segments are produced by ties.

Figure 1: Discrimination power of each model at the probability of giving birth at health institutions among ANC attendants, West Shewa, January 2010

\section{Discussion}

In this article, we modeled the probability of giving birth at health institutions among women attending ANC service using multivariate logistic regression analysis. Four logistic regression models were indentified to estimate the probability of giving birth at health institution in the study population. The first model consisted of socio-demographic variables of the participants. In this regression model, household monthly income and husband occupation had positively predicted the probability of giving birth at health institutions while the type of health institutions (being attending ANC at health center) and mother occupation were negatively predicted the probability. Some previous research finding also support this prediction $[20,21]$. This prediction model told us that being attending ANC at health centers reduce the probability of positive outcome (giving birth at health institutions) implying that mothers who follow ANC service at health center tend to deliver at home. This could be a serious challenge to promote safe delivery service as most of ANC service is being provided at health center level. According to classification accuracy rate, the overall accuracy of this model to predict mothers who will give at health institutions was $72.7 \%$; sensitivity (81.5\%), specificity (56.4\%), Positive Predictive Value (PPV) $(77.4 \%)$ and Negative Predictive Value (NPV) of $62.3 \%$. However, looking at its discrimination power from the ROC curve, the approximated optimum sensitivity and specificity was achieved at $80 \%$ and $70 \%$ respectively. This implies that this regression model had fair discrimination power. In the second regression model, age at first pregnancy and gravida had positive effect on the predicted probability. For instance, an increase in one-year age of mother had a 39.9\% (95\% CI $15.0 \%$ to $68.0 \%$ ) increase in odds of giving birth at health institutions. The number of pregnancy (gravid) had also similar effects. This implies that mothers tend to seek modern obstetric care for their subsequent pregnancies than first, second or third pregnancies. 
This finding is in contrast with previous research reports [22, 23]. However, evidence also supports that grand multiparas and primiparas are at greatest risk of maternal mortality and morbidity as well as having poor delivery outcome $[24,25]$. Similarly, increasing age at first pregnancy associated with increasing probability of giving birth at health institutions which was also supported by literature [26].

On the other hand, being unable to make her own decision where to deliver and not receiving health information during the ANC visit had significantly associated decreased probability of the positive outcome. Based on classification accuracy table output, the overall classification accuracy rate of this model was $84.4 \%$ with sensitivity (92.1\%), specificity (65.1\%), PPV $(86.8 \%)$ and NPV (76.7\%). A close look into the ROC curve showed that this regression model had achieved more specificity $(80.0 \%)$ than sensitivity $(76.0 \%)$ and it indicates that the ability to discriminate between those mothers who will give birth at health institution and home was very low; which means that in almost $81.4 \%$ (area under the curve) of all possible pairs of subjects this model assigned a higher probability to the subjects who intended to give birth at home.

In the third regression model, except perceived barriers, all constructs of health belief model (perceived susceptibility, perceived severity, perceived benefits, self efficacy and cues to actions) were significantly associated with increased probability to give birth at health institutions $(p<0.05)$. Self efficacy scale achieved the highest positive effect; a unit increase in score to the scale was resulted on average 0.49 increases in intention to give birth at health instructions. However, the higher the score to perceived barrier scale was significantly associated with decreasing the probability of the positive outcome. Concerning classification accuracy rate, this regression model had the same statistics with the second regression model. However, it was more sensitive $(90.0 \%)$ but lower specificity $(65.0 \%)$. Thus, in contrary to the second model, it was highly overestimated the proportion of mothers who will give birth at health institutions. In other words, false positive rate might be a problematic in this regression model. The last regression model which consisted of all significant predictors in the previous three regression models was found to be stable in predicting the probability of giving birth at health institutions in this data set. It achieved an optimum sensitive (89.0\%) and specificity $(80.0 \%)$. This reflects this regression model has good power of discriminating subjects who will give birth at health institutions and home and deemed utility to predict the probability of giving birth at health institutions. Cross validation statistics also favoring the utility of this regression model. In this model, perceived susceptibility, perceived barriers, self efficacy, being able to make decision on her own and being informed by health professionals where to delivery significantly continued to predict the probability. This implies that the probability of giving birth at health institution can be predicted on the basis of these factors.

\section{Conclusion}

Taken as a whole, four logistic regression models were developed to estimate the probability of giving birth in health institutions. The first three models were unstable to predict the outcome of interest. However, the last regression model which consisted of all covariates was found to be more stable, achieved better sensitivity and specificity and deemed utility to predict the outcome of interest. Thus, the study concluded that the probability of giving birth at health institution increased with higher perceived susceptibility to birth complication, higher self efficacy to control the behavior, being informed by health professionals and making decision by others. Therefore, we recommend health care providers should take into account these factors to promote institutional delivery. However, the study was facility based and may not be generalized to all pregnant women and it deems further study particularly in community setups.

\section{Acknowledgements}

We acknowledge Jimma University for funding this study. We are also grateful to the study participants for their voluntary participation.

\section{Competing interests}

Authors declared they have no conflicts of interest.

\section{Authors' contributions}

$\mathrm{ZB}, \mathrm{ND}, \mathrm{DT}$ and SM conceived and designed the study. $\mathrm{ZB}$ and $\mathrm{MG}$ analyzed the data. ZB and MG analyzed, drafted and critically reviewed the manuscript. All authors have read and approved this manuscript. 


\section{References}

1. United Nations. The children and Millennium Development Goals. Progress towards a World Fit for Children. 2007. New York

2. Embargo. Meeting MDG-5: an impossible dream? 2009. London

3. United Nations. The Millennium Development Goals Report. 2008.New York

4. Federal Democratic Republic of Ethiopia. Demographic and Health Survey Report. 2005.Addis Ababa

5. Ministry of Health $(\mathrm{MOH})$, Kenya. A question of survival? Review of safe motherhood: Ministry of Health - Division of Primary Health Care. 1997. Nairobi

6. Obermeyer C, Potter J. Maternal health care utilisation patterns in Jordan: a study of patterns and determinants. Studies in Family Planning. 1991; 22 (3): 177-187

7. World Health Organization. World Health statistics. 2009. France

8. Federal Democratic republic of Ethiopia/Ministry of Finance and Economic Development. Trends and prospect for meeting MDGs by 2015. 2010.Addis Ababa

9. Mekonnen Y, Mekonnen A. Utilization of Maternal Health Care Services in Ethiopia. Ethiopian Health and Nutrition Research Institute, Ethiopia. Addis Ababa; 2002

10. Julia A. The development of maternal confidence for labor among nulliparous pregnant women. $\mathrm{PhD}$ thesis. 2003. University of Maryland. Department of Public Health and Community Health

11. WHO Regional Office for South-East Asia. Highlevel consultation to accelerate progress towards achieving maternal and child health Millennium Development Goals (MDGs) 4 and 5 in South-East Asia. Ahmedabad India. 2008; 14-17

12. Teguh S. Knowledge and Practice of Maternal Health Care in Indonesia. Journal Kependudukan Indonesia. 2007; 2(2): 1-19

13. Anuja J, Chandrasekhar S, Gebreselassie T. Factors Affecting Maternal Health Care Seeking Behavior in Rwanda. Demographic and Health Research. 2008
14. Rose NM Mpembeni, Japhet Z Killewo, Melkzedeck T Leshabari, Siriel N Massawe, Albrecht Jahn, Declare Mushi, Hassan Mwakipa . Use pattern of maternal health services and determinants of skilled care during delivery in Southern Tanzania: implications for achievement of MDG-5 targets. BMC Pregnancy and Childbirth. 2007; 7:29

15. Idris S, Gwarzo D, Shehu U. Determinants of Place of Delivery among women are Semi- Urban Settlement in Zaria, North Nigeria. Annals of African Medicine. 2006; 2(5): 68-72

16. West Shewa Zonal Health Department. West Shewa first quarter health statistic report 2009 (Un-published) 17. .Nigussie M. et al. Assessment of safe delivery service utilization among women of childbearing age in north Gondar Zone, North west Ethiopia. Ethiopia. J. Health Dev. 2004; 18(3):145-152

18. Rosenstock I. Historical Origins of the Health Belief Model. Health Education Monographs.1974; 2(4)

19. Glanz K, Rimer B, Lewis F. Health Behavior and Health Education: Theory, Research and Practice- $3^{\text {rd }}$ edition.2002. San Francisco. Wiley \& Sons

20. Iyaniwural CA, Yussuf Q. Utilization of Antenatal care and Delivery services in Sagamu, South Western Nigeria. Afr J Reprod Health. 2009; 13(3):111-122

21. Navaneetham K, Dharmalingam A. Utilization of maternal health care services in south india. Soc Sci Med. 2002; 55(10):1849-69

22. Nigussie M, Haile D, Mitike G. Assessment of safe delivery service utilization among women of childbearing age in north Gondar Zone, North West Ethiopia. Ethiop.J.Health Dev. 2004; 18(3):145-152

23. Ethiopian Society of Population Studies. Maternal Health Care Seeking Behavior in Ethiopia: Findings from EDHS 2005. Addis Ababa; 2008

24. Tessema F, Asefa M, Ayele B. Mothers' health services utilization and health care seeking behavior during infant rearing: A longitudinal community based study, southwest Ethiopia. Ethiop J. Health Dev. 2002; 16: $51-58$

25. Bhardawaji N, Badrul Hasan S, Yunus M, Zahara $\mathrm{M}$. High risk pregnancy and relation with maternal care receptivity: A rural study from India. Journal of the Royal Society of Health. 1991; 111: 43-46

26. Mustafizur N. Determinants of Maternal Health Care Utilization in Bangladesh. Research Journal of Applied Sciences. 2009; 4(3): 113-119 